\title{
ANALISIS SISTEM PERSAMAAN DIFERENSIAL MODEL PREDATOR-PREY DENGAN PERLAMBATAN
}

\author{
Vivi Aida Fitria \\ Dosen STMIK STIE Asia Malang \\ e-mail:v2_dz@yahoo.com
}

\begin{abstract}
ABSTRAK
Model predator-prey dengan perlambatan merupakan model interaksi dua spesies antara mangsa dan pemangsa yang berbentuk sistem persamaan diferensial tak liner. Adanya waktu perlambatan sangat mempengaruhi kestabilan titik ekuilibrium sistem persamaan diferensial model predator-prey. Penelitian ini bertujuan untuk menganalisis pengaruh waktu perlambatan terhadap kestabilan titik ekuilibrium sistem persamaan diferensial model predator-prey. Namun sebelum itu, agar dapat diketahui asal mula pembentukan model predator-prey dengan perlambatan akan dianalisis proses terbentuknya model predator-prey dengan perlambatan. Penelitian ini menggunakan penelitian kepustakaan, yaitu dengan menampilkan argumentasi penalaran keilmuan yang memaparkan hasil kajian literatur dan hasil olah pikir peneliti mengenai suatu permasalahan atau topik kajian. Hasil penelitian ini menunjukkan bahwa ada beberapa nilai perlambatan yang menyebabkan titik ekuilibrium sistem persamaan diferensial model predator-prey stabil, dan ada beberapa nilai perlambatan yang menyebabkan titik ekuilibrium sistem persamaan diferensial model predator-prey tidak stabil.
\end{abstract}

Kata Kunci: Sistem Persamaan Diferensial, Titik Ekuilibrium, Kestabilan, Perlambatan.

\section{ABSTRACT}

Predator-prey model with the deceleration is a model of two species interactions between prey and predator in the form of differential equations system is not linear. The existence of deceleration time greatly affects the stability of the equilibrium point differential equations system of predator-prey model. This study aims to analyze the effect of time slowing down of the stability of the equilibrium point differential equations system of predator-prey model. But before that, in order to know the origin of the formation of predator-prey models with the slowdown will be analyzed the process of formation of predator-prey model with deceleration. This study uses the research literature, namely by presenting scientific arguments reasoning that presents the results of literature review and the results if the researcher thinks about an issue or topic of study. The results of this study indicate that there are some values that cause the equilibrium point deceleration system of differential equations model of predatorprey stable, and there are some values that cause the equilibrium point deceleration system of differential equations predator-prey model is unstable.

Keywords: Differential Equation System, Equilibrium Points, Stability, Deceleration.

\section{PENDAHULUAN}

Peningkatan jumlah populasi tanpa batas waktu tertentu tidak akan mungkin terjadi baik di laboratorium maupun di alam. Misalnya yang terjadi pada sebuah bakteri. Bakteri dapat bereproduksi dengan cara pembelahan setiap 20 menit dengan kondisi laboratorium yang ideal. Setelah 20 menit, akan terdapat dua bakteri, empat bakteri setelah 40 menit, dan demikian seterusnya. Jika keadaan ini berlangsung terus selama satu setengah hari -hanya 36 jam sajaakan terdapat bakteri yang cukup untuk membentuk suatu lapisan setebal satu kaki. Darwin menghitung bahwa hanya memerlukan 750 tahun bagi sepasang gajah untuk menghasilkan populasi 19 juta gajah (Campbell, 2004 :344).

Pada tulisan ini akan dibahas tentang analisis kestabilan model predator-prey atau analisis kestabilan model mangsa-pemangsa. Dari model predator-prey yang stabil akan terciptalah lingkungan yang seimbang. Model ini digambarkan dalam suatu persamaan matematika. Persamaan ini merupakan pendekatan terhadap suatu fenomena fisik. Persamaan yang digunakan adalah persamaan diferensial. Persamaan diferensial adalah persamaan yang di dalamnya terdapat turunanturunan. (Frank Ayres, $1992: 1$ )

Dengan model dapat digambarkan suatu fenomena sehingga menjadi lebih jelas dalam memahaminya. Dan dengan adanya model 
predator-prey ini, memudahkan para ahli untuk dapat memproyeksikan populasi/spesies pada suatu waktu tertentu atau menekan laju populasi agar tetap seimbang.

Dari waktu ke waktu bentuk model predator-prey dimodifikasi sehingga dapat menggambarkan dengan dengan teliti keadaan sebenarnya. Begitupula model predator-prey, berawal dari model yang sederhana yang diperkenalkan oleh Lotka-Voltera, sampai pada model predator-prey dengan perlambatan.

Di dalam model predator-prey dengan perlambatan dipertimbangkan waktu tunda dari prey pada saat memasuki masa sebelum melahirkan. Dengan adanya waktu perlambatan inilah menyebabkan titik ekuilibrium model tidak stabil. Berdasarkan permasalahan tersebut dapat dibahas atau dikaji lebih jauh tentang model predator-prey dengan perlambatan. Adapun fokus dalam tulisan ini adalah 1) untuk menganalisis pembentukan model predator-prey dengan perlambatan, dan 2) untuk mengetahui pengaruh waktu perlambatan terhadap kestabilan titik ekuilibrium sistem persamaan diferensial model predator-prey dengan perlambatan.

\section{KAJIAN TEORI}

\section{Sistem Persamaan Diferensial \\ Definisi 1 :}

Sistem persamaan diferensial adalah suatu sistem yang memuat $\mathrm{n}$ buah persamaan diferensial, dengan $\mathrm{n}$ buah fungsi yang tidak diketahui, dimana $\mathrm{n}$ merupakan bilangan bulat positif lebih besar sama dengan 2 (Finizio dan Ladas, 1982:132). Antara persamaan diferensial yang satu dengan yang lain saling keterkaitan dan konsisten.

Bentuk umum dari suatu sistem $n$ persamaan orde pertama mempunyai bentuk sebagai berikut :

$$
\begin{aligned}
& \frac{d x_{1}}{d t}=g_{1}\left(t, x_{1}, x_{2}, \ldots, x_{n}\right) \\
& \frac{d x_{2}}{d t}=g_{2}\left(t, x_{1}, x_{2}, \ldots, x_{n}\right) \\
& \vdots \\
& \frac{d x_{n}}{d t}=g_{n}\left(t, x_{1}, x_{2}, \ldots, x_{n}\right)
\end{aligned}
$$

Dengan $x_{1}, x_{2}, \ldots x_{n}$ adalah variabel bebas dan $t$ adalah variabel terikat, sehingga $x_{1}=x_{1}(t), x_{2}=x_{2}(t), \ldots x_{n}=x_{n}(t)$, dimana $\frac{d x_{n}}{d t}$ merupakan derivatif fungsi $x_{n}$ terhadap t, dan $g_{i}$ adalah fungsi yang tergantung pada variabel $x_{1}, x_{2}, \ldots x_{n}$ dan $t$ (Claudia, 2004:702).

\section{Sistem Otonomus}

Definisi 2 :

Sistem otonomus adalah suatu sistem persamaan diferensial yang berbentuk

$$
\dot{x}=f(x, y) \quad \dot{y}=g(x, y)
$$

dimana fungsi-fungsi $f$ dan $g$ bebas dari waktu (Finizio dan Ladas, 1982:287).

\section{Definisi 3:}

Jika $\hat{y}$ memenuhi

$$
g(\hat{y})=0
$$

maka $\hat{y}$ adalah sebuah titik ekuilibrium dari

$$
\frac{d y}{d x}=g(y) \quad \text { (Claudia, 2004:494) }
$$

\section{Contoh :}

$\dot{x}=-y$,

$$
\dot{y}=x
$$

Titik ekuilibrium persamaan (2.3) ditentukan oleh dua persamaan $-y=0, x=0$. Jadi $(0,0)$ merupakan satu-satunya titik ekuilibriumdari persamaan (2.3).

Jika sistem otonomus (2.2) linier dengan koefisien konstan, maka sistem otonomus tersebut berbentuk :

$$
\dot{x}=a x+b y \quad \dot{y}=c x+d y
$$

dengan $a, b, c$, dan $d$ adalah konstanta. Jika dimisalkan $a d-b c \neq 0$ maka titik $(0,0)$ adalah satu-satunya titik kritis persamaan (2.4) dan persamaan karakteristiknya berbentuk :

$\lambda^{2}-(a-d) \lambda+(a d-b c)=0$

dengan $\lambda_{1}$ dan $\lambda_{2}$ adalah akar-akar persamaannya. Sehingga terdapat teorema berikut :

\section{Teorema 1}

a. Titik kritis $(0,0)$ dari sistem (2.4) stabil, jika dan hanya jika, kedua akar dari persamaan (2.5) adalah riil dan negatif atau mempunyai bagian riil takposistif.

b. Titik kritis $(0,0)$ dari sistem (2.4) stabil asimtotis, jika dan hanya jika, kedua akar dari persamaan (2.5) adalah riil dan negatif atau mempunyai bagian riil negatif.

c. Titik kritis $(0,0)$ dari sistem (2.4) tak stabil, jika salah satu (atau kedua akar) akar dari persamaan (2.5) adalah riil dan positif atau jika paling sedikit satu akar mempunyai bagian riil posistif (Finizio dan Ladas, 1982:293).

Sistem persamaan diferensial tak linier seringkali muncul dalam penerapan, misalnya dalam model predator-prey. Tetapi hanya beberapa tipe persamaan diferensial tak linier yang dapat diselesaikan secara eksplisit. Sedangkan persamaan diferensial tak linier yang 
tidak dapat diselesaikan secara eksplisit, dapat diselesaikan dengan melinierkan terlebih dahulu.

Sistem (2.2) dari dua persamaan diferensial tak linier dengan dua fungsi yang tak diketahui berbentuk :

$\dot{x}=a x+b y+P(x, y)\}$

$\dot{y}=c x+d y+Q(x, y)\}$

dimana a, b, c, d, P, Q memenuhi syarat :

a. a, b, c dan d konstanta real dan $\left|\begin{array}{ll}a & c \\ d & b\end{array}\right| \neq 0$

b. $P(x, y)$ dan $Q(x, y)$ mempunyai derivatif parsial kontinu untuk semua $(\mathrm{x}, \mathrm{y})$ dan memenuhi :

$$
\begin{aligned}
\lim _{(x, y) \rightarrow(0,0)} \frac{P(x, y)}{\sqrt{x^{2}+y^{2}}} & =\lim _{(x, y) \rightarrow(0,0)} \frac{Q(x, y)}{\sqrt{x^{2}+y^{2}}} \\
& =0
\end{aligned}
$$

sehingga sistem linearnya berbentuk

$\dot{x}=a x+b y$

$\dot{y}=c x+d y$

Dari syarat di atas maka berlaku :

\section{Teorema 2}

a. Titik kritis $(0,0)$ dari sistem tak linier (2.6) adalah stabil asimtotis jika titik kritis $(0,0)$ dari sistem yang dilinierkan (2.7) adalah stabil asimtotis.

b. Titik kritis $(0,0)$ dari sistem taklinier (2.6) adalah takstabil jika titik kritis $(0,0)$ dari sistem (2.7) adalah takstabil.

Teorema ini tidak memberikan kesimpulan mengenai sistem (2.6) bila $(0,0)$ hanya merupakan titik stabil dari sistem (2.7). (Finizio dan Ladas, 1982:294).

\section{Model Matematika}

Pemecahan masalah dalam dunia nyata dengan matematika dilakukan dengan mengubah masalah tersebut menjadi bahasa matematika, proses tersebut disebut pemodelan secara matematik atau model matematika. (Baiduri, 2002:1). Jadi pemodelan matematika dapat dipandang sebagai terjemahan dari fenomena atau masalah menjadi permasalahan matematika. Informasi matematika yang diperoleh dengan melakukan kajian matematika atas model tersebut dilakukan sepenuhnya dengan menggunakan kaedah-kaedah matematika. Syarat utama model yang baik adalah sebagai berikut :

a. Representatif: model mewakili dengan benar sesuatu yang diwakili, makin mewakili, model makin kompleks.

b. Dapat dipahami/dimanfaatkan: model yang dibuat harus dapat dimanfaatkan (dapat diselesaikan secara matematis), makin sederhana makin mudah diselesaikan.
Langkah-langkah dalam pemodelan masalah digambarkan dalam diagram berikut :

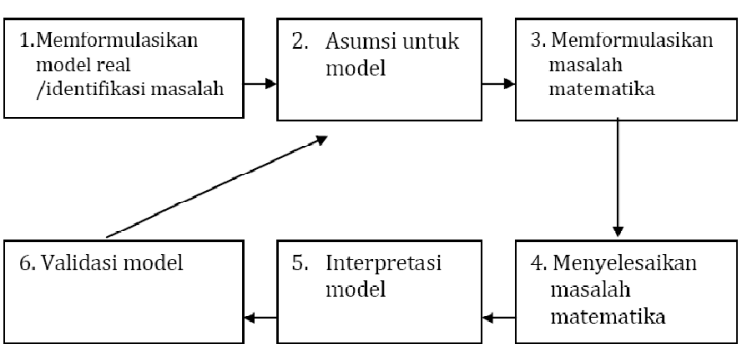

Keterangan :

1. Identifikasi masalah, yaitu mampu memahami masalah yang akan dirumuskan sehingga dapat ditranslasi ke dalam bahasa matematika

2. Membuat asumsi, yaitu dengan cara menyederhanakan banyaknya faktor yang berpengaruh terhadap kejadian yang sedang diamati dengan mengasumsi hubungan sederhana antara variabel. Asumsi tersebut dibagi dalam dua kategori utama :

a. Klasifikasi variabel

Pemodel mengidentifikasi variabel terhadap hal-hal yang mempengaruhi tingkah laku pengamatan

b. Menentukan interelasi antara variabel yang terseleksi untuk dipelajari

Pemodel membuat sub model sesuai asumsi yang telah dibuat pada model utama, kemidian mempelajari secara terpisah pada satu atau lebih variabel bebas.

3. Menyelesaikan atau menginterpretasikan model

Setelah model diperoleh kemudian diselesaikan secara matematis, dalam hal ini model yang digunakan dan penyelesaiannya menggunakan persamaan diferensial. Apabila pemodel mengalami kesulitan untuk menyelesaikan model dan interpretasi model, maka kelangkah 2 dan membuat asumsi sederhana tambahan atau kembali kelangkah 1 untuk membuat definisi ulang dari permasalahan. Penyederhanaan atau definisi ulang sebuah model merupakan bagian yang penting dalam matematika model.

4. Verifikasi model

Sebelum menyimpulkan kejadian dunia nyata dari hasil model, terlebih dahulu model tersebut harus diuji. Beberapa pertanyaan yang diajukan sebelum melakukan uji dan mengumpulkan data, yaitu : 1) apakah model menjawab masalah yag telah diidentifikasi? 2) apakah model membuat pemikiran yang sehat? 3) apakah data (sebaiknya menggunakan data aktual yang diperoleh 
dari observasi empirik) dapat dikumpulkan untuk menguji dan mengoperasikan model dan apakah memenuhi syarat apabila diuji (Baiduri, 2002:15-17).

\section{Model Logistik}

Model logistik atau model Verhulst atau kurva pertumbuhan logistik adalah sebuah model pertumbuhan populasi. Model logistik termasuk model yang memiliki waktu kontinu. Model tersebut dideskripsikan sebagai berikut:

$$
\frac{d x}{d t}=r x\left(1-\frac{x}{K}\right)
$$

Konstanta r, diasumsikan positif. Konstanta $r$ adalah laju pertumbuhan intrinsik karena perbandingan laju pertumbuhan untuk $\mathrm{x}$ diperkirakan sama dengan $\mathrm{r}$. Konstanta positif $\mathrm{K}$ biasanya mengarah kepada daya kapasitas kesehatan lingkungan yaitu kemampuan menahan populasi agar tetap maksimum. Solusi dari model logistik tersebut adalah :

$$
x(t)=\frac{x_{0} K}{x_{0}+\left(K-x_{0}\right) e^{-r t}}
$$

Model logistik mempunyai dua titik ekuilibrium, yaitu $\mathrm{x}=0$ dan $\mathrm{x}=\mathrm{K}$. Titik ekulibrium pertama tidak stabil sementara titik ekuilibrium kedua adalah stabil global. Beberapa kurva dari solusi model logistik dengan titik awal yang berbeda dapat dilihat pada Grafik 2.1.

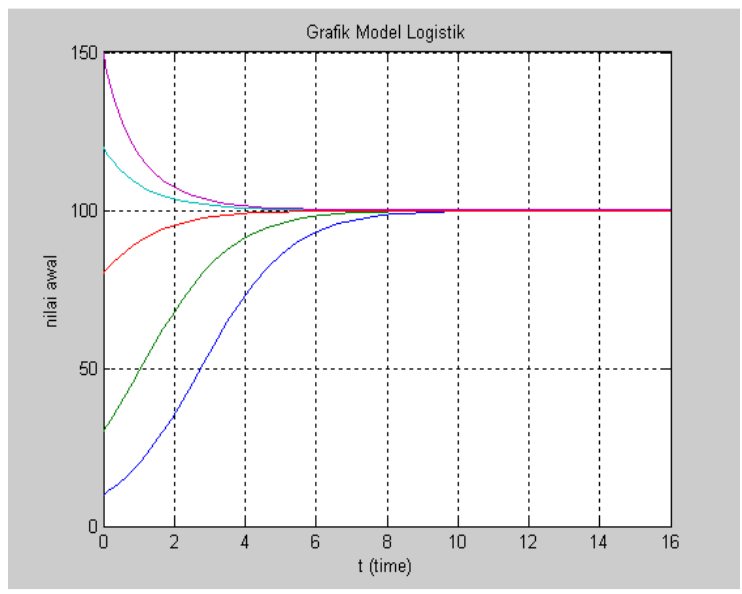

Gambar 2.1. Grafik Model Logistik dari

Persamaan (2.9) dengan $\mathrm{K}=100$,r=1 dan Lima Kondisi Awal Masing-Masing $\mathrm{x}(0)=10, \mathrm{x}(0)=30$, $x(0)=80, x(0)=120$ dan $x(0)=150$

\section{Model Logistik dengan Perlambatan} tan adalah

Model logistik tunggal dengan perlamba-

$$
\frac{d x(t)}{d t}=r x(t)\left(1-\frac{x(t-\tau)}{K}\right),
$$

dimana $\tau$ adalah sebuah waktu perlambatan dan dianggap positif. Suatu titik ekuilibrium positif dari model ini adalah K. Hal ini diusulkan oleh Hutchinson di Gopalsamy, model (2.10) tersebut bisa digunakan pada model pertumbuhan populasi jenis dinamik tunggal terhadap ketahanan level $\mathrm{K}$, dengan sebuah konstanta laju pertumbuhan intrinsik $r$. Bentuk $\left(1-\frac{x(t-\tau)}{K}\right)$ pada model (2.10) merupakan sebuah kepadatan tergantung pada mekanisme pengaruh arus balik yang mengambil $\tau$ satuan waktu untuk menanggapi perubahan pada kepadatan populasi diwakili pada model (2.10) oleh $x$. Model logistik dengan perlambatan (2.10) dikenal sebagai persamaan perlambatan Verhulst atau persamaan Hutchinson. Persamaan Hutchinson telah dipelajari di beberapa jurnal dan buku.

Selanjutnya akan dianalisis stabilitas lokal dari titik ekuilibrium. Untuk menganalisis, digunakan sebuah metode standar yaitu metode linierisasi disekitar titik ekuilibrium. Misalkan $u(t)=x(t)-K$, maka $\frac{d u(t)}{d t}=\frac{d x(t)}{d t}$.

Mensubtitusi $\quad x(t)=u(t)+K \quad$ ke dalam persamaan (2.10) untuk memperoleh

$$
\begin{aligned}
& \frac{d u(t)}{d t}=r(u(t)+K)\left(1-\frac{u(t-\tau)+K}{K}\right) \\
& \frac{d u(t)}{d t}=\frac{-r}{K} u(t) u(t-\tau)-r u(t-\tau) .
\end{aligned}
$$

Karena $\mathrm{x}(\mathrm{t})$ tertutup untuk $\mathrm{K}, u(t) u(t-\tau)$ dapat dihilangkan. Selanjutnya didapatkan suatu model linier

$$
\frac{d u(t)}{d t}=-r u(t-\tau) \text {. }
$$

Untuk memahami stabilitas titik ekuilibrium nol dari model (2.12), dipertimbangkan persamaan karakteristik pada model (2.12). Pensubtitusian pada fungsi tes $x(t)=e^{\lambda \tau}$ ke dalam model (2.12) menghasilkan persamaan karakteristik

$$
\lambda e^{\lambda \tau}=-r e^{\lambda(t-\tau)}
$$

karena $e^{\lambda \tau} \neq 0$, maka

$$
\lambda+r e^{-\lambda \tau}=0 \text {. }
$$

Lemma 1 Misalkan $r>0$ dan $\tau>0$ jika $\tau \leq \frac{1}{r e}$ maka persamaan (2.13) memiliki akar-akar persamaan karakteristik negatif

\section{Bukti}

Misalkan $F(\lambda)=\lambda+r e^{-\lambda \tau}$. Dengan catatan bahwa $\lambda$ bukan bilangan riil nonnegatif. Akan dibuktikan bahwa akar-akar dari $F(\lambda)$ adalah bukan bilangan komplek. Karena $F(\lambda)=\lambda+r e^{-\lambda \tau}$ 
maka $F^{\prime}(\lambda)=1-r \tau e^{-\lambda \tau}$ dan $\lambda_{*}=\frac{1}{\tau} \ln (r \tau)$ adalah titik kritik dari $F(\lambda)$ Oleh karena itu, $F^{\prime \prime}(\lambda)=r \tau^{2} e^{-\lambda \tau}$ yang positif. Ini berarti bahwa nilai dari titik kritik memberikan nilai minimum untuk $\quad F(\lambda)$. Selanjutnya karena $F\left(\lambda_{*}\right)=\frac{1}{\tau}(\ln (r \tau)+1)$ yang sama dengan nol jika $r \tau=\frac{1}{e}$ atau $\left(\tau=\frac{1}{r e}\right)$, dan kurang dari nol jika $\tau<\frac{1}{r e}$ maka persamaan (2.13) hanya memiliki satu akar, yaitu $\tau=\frac{1}{r e}$, dan jika $\lambda=\frac{1}{\tau} \ln (r \tau)$ persamaan (2.13) memiliki dua akar riil negatif.

$$
\text { Jika } F\left(\lambda_{\bullet}\right)>0, \quad \text { yaitu } \quad r \tau>\frac{1}{e}, \quad \text { ini }
$$

mengakibatkan bahwa tidak ada akar riil dari persamaan karakteristik (2.13). Kondisi persamaan karakteristik ini mempunyai akar komplek konjugat. Jika dimisalkan $\lambda=\rho+i \omega$, $\rho \in R, \omega \in[0, \infty)$, sebagai sebuah akar dari (2.13), maka

$$
\begin{aligned}
\rho+i \omega & =-r e^{-(\rho+i \omega) \tau} \\
& =-r e^{-\rho \tau}(\cos (\omega \tau)-i \sin (\omega \tau))^{\prime}
\end{aligned}
$$

maka didapatkan dua persamaan dengan bagian riil dan bagian imajinernya:

$$
\begin{aligned}
& \rho=-r e^{-\rho \tau} \cos (\omega \tau), \\
& \omega=r e^{-\rho \tau} \sin (\omega \tau) .
\end{aligned}
$$

(Syamsuddin, 2006:3.7).

Lemma 2 Misalkan $\quad r>0 \quad$ dan $\tau>0$. Jika $\frac{1}{r e}<\tau<\frac{\pi}{2 r}$ maka akar dari persamaan karakteristik (2.13) adalah komplek konjugat dengan bagian riil negatif.

\section{Bukti}

Misalkan $F(\lambda)=\lambda+r e^{-\lambda \tau}$. Dari persamaan (2.13) bahwa $\lambda$ bukan bilangan riil nonnegatif. Maka $F^{\prime}(\lambda)=1-r \tau e^{-\lambda \tau}$ dan $\lambda_{\bullet}=\frac{1}{\tau} \ln (r \tau)$ adalah sebuah titik ekuilibrium untuk $F(\lambda)$. Selanjutnya $F^{\prime \prime}(\lambda)=r \tau^{2} e^{-\lambda \tau}$ adalah positif. Ini berarti bahwa nilai dari titik ekuilibrium memberi nilai minimum untuk $F(\lambda)$. Fungsi $F(\lambda)$ tidak mempunyai akar riil dimana $F\left(\lambda_{\bullet}\right)=\frac{1}{\tau}(\ln (r \tau)+1)>0$ dan ini terjadi ketika $\frac{1}{r e}<\tau$. Sekarang akan ditunjukkan bahwa akar dari $F(\lambda)$ adalah sebuah bilangan komplek dengan bagian riil negatif. Misalkan persamaan (2.13) tersebut mempunyai akar $\lambda=\rho+i \omega$ dengan $\rho \geq 0$. Karena $\lambda=0$ adalah bukan akar dari persamaan karakteristik (2.13) dan diasumsikan $\omega>0$ hal ini menunjukkan (dari persamaan (2.14b)) bahwa

$$
0<\omega \tau=r \tau e^{-\rho \tau} \sin \omega \tau<\frac{\pi}{2}
$$

Hal ini menunjukkan bahwa sisi kiri dari persamaan (2.14a) adalah nonnegatif. Karena kontradiksi hal ini membuktikan bahwa $\rho<0$. Perhatikan konjugat dari $\lambda$ membuktikan persamaan karakteristik (2.13) (Syamsuddin, 2006: 3.9).

Berikut adalah kurva dari solusi model logistik dengan beberapa nilai perlambatan berbeda :

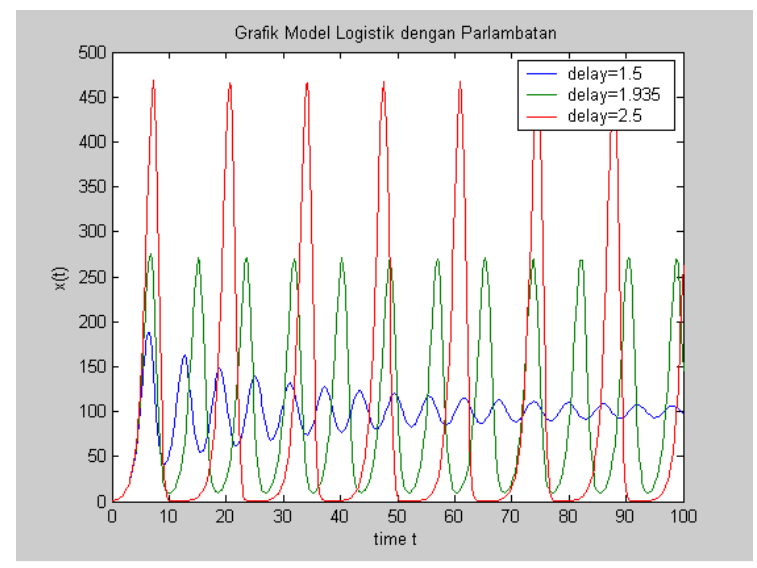

Gambar 2.2. Grafik Model Logistik dari

Persamaan (2.10) dengan $\mathrm{K}=100, \mathrm{r}=1$ dan Tiga Nilai Perlambatan Yaitu $\tau=1.5, \tau=1.935$ dan

$$
\tau=2.5
$$

\section{Model Populasi Predator-Prey}

Dalam subbab ini, dibahas tentang model sederhana dari predator-prey, yang didefinisikan sebagai konsumsi predator terhadap prey. Model predator-prey yang paling sederhana didasarkan pada model Lotka-Volterra (Lotka, 1932 ; Volterra, 1926) dalam Claudia (2004:760) , yang dideskripsikan dalam kata-kata Volterra, sebagai berikut :

"Kasus pertama yang saya pertimbangkan adalah bahwa ada dua jenis hubungan. Yang pertama menemukan makanan yang cukup di lingkungannya dan akan berkembang terus meskipun hidup sendirian, dan yang kedua mati karena kekurangan makanan jika dibiarkan hidup sendiri. Tetapi makanan yang kedua untuk 
makanan yang pertama. Sehingga dua jenis ini dapat hidup berdampingan. Angka perbandingan dari kenaikan jenis makanan dikurangi jumlah individu dari pertumbuhan jenis makanan, saat tambahan jenis makanan berkembang seiring dengan berkembangnya jumlah individu dari jenis makanan. "

Model Lotka-Voltera tersusun dari pasangan persamaan diferensial yang mendeskripsikan predator-prey dalam kasus yang paling sedehana. model ini membuat beberapa asumsi :

1. Populasi prey akan tumbuh secara eksponen ketika tidak adanya predator

2. Populasi predator akan mati kelaparan ketika tidak adanya populasi prey

3. Predator dapat mengkonsumsi prey dengan jumlah yang tak terhingga

4. Tidak adanya lingkungan yang lengkap (dengan kata lain, kedua populasi berpindah secara acak melalui sebuah lingkungan yang homogen)

Selanjutnya bentuk verbal ini diterjemahkan ke dalam sebuah sistem persamaan diferensial. Diasumsikan bahwa populasi prey berkurang ketika predator membunuhnya dan bertahan hidup (tidak mengurangi populasi prey) ketika predator hanya menyerangnya. Model dengan laju perubahan dari populasi prey $(\mathrm{x})$ dan populasi predator $(\mathrm{y})$ adalah :

$$
\begin{aligned}
& \frac{d x}{d t}=r x\left(1-\frac{x}{K}\right)-\alpha x y \\
& \frac{d y}{d t}=-c y+\beta x y
\end{aligned}
$$

Parameter model di atas yaitu :

$\mathrm{K}$ = daya kapasitas

$\mathrm{r} \quad$ = laju pertumbuhan intrinsik prey

c = laju kematian jika predator tanpa prey

$\alpha \quad=$ laju perpindahan dari prey ke predator

$\beta \quad$ = laju pepindahan dari predator ke prey

Model di atas dibentuk dengan analisis sebagai berikut :

Dimulai dengan memperhatikan apa yang terjadi pada populasi predator ketika tidak adanya prey, tanpa sumber makanan, bilangannya diharapkan berkurang secara eksponensial, dideskripikan oleh persamaan di bawah ini :

$$
\frac{d y}{d t}=-c y
$$

Persamaan ini menggunakan hasil kali dari bilangan predator (y) dan kelajuan kematian predator (c). Untuk mendeskripsikan penurunan kelajuan (karena tanda negatif pada bagian kanan persamaan) dari populasi predator dengan pengaruh waktu. Dengan adanya prey bagaimanapun juga pengurangan ini dilawan oleh laju kelahiran predator, yang ditentukan oleh laju konsumsi ( $\beta x y$ ). Dimana laju penyerangan $(\beta)$ dikalikan dengan bilangan y dan bilangan $\mathrm{x}$. Bilangan predator dan prey naik ketika pertemuan predator dan prey lebih sering, tetapi laju aktual dari konsumsi akan tergantung pada laju penyerangan $(\beta)$. Persamaan populasi predator menjadi

$$
\frac{d y}{d t}=-c y+\beta x y
$$

Perkalian $\beta$ y adalah tanggapan predator secara numerik atau peningkatan perkapita dari fungsi prey yang melimpah. Dan untuk perkalian $\beta$ xy menunjukkan bahwa kenaikan populasi predator sebanding dengan perkalian dan prey yang melimpah.

Beralih pada populasi prey, kita berharap tanpa serangan predator, bilangan prey akan naik secara eksponensial. Persamaan di bawah ini mendeskripsikan laju kenaikan populasi prey dengan pengaruh waktu, dimana $r$ adalah laju pertumbuhan intrinsik prey dan $\mathrm{x}$ adalah jumlah dari populasi prey.

$$
\frac{d x}{d t}=r x
$$

Di hadapan predator, bagaimanapun juga populasi prey dicegah dari peningkatan eksponensial secara terus-menerus. Karena model predator prey memiliki waktu yang kontinu dan mengisyaratkan tentang model pertumbuhan populasi maka termasuk dalam model logistik. Jadi persamaan di atas menjadi:

$$
\frac{d x}{d t}=r x\left(1-\frac{x}{K}\right)
$$

Dengan adanya predator bagaimanapun juga kenaikan ini dilawan oleh laju kematian prey karena adanya penyerangan dari predator, yang ditentukan oleh laju konsumsi ( $\alpha x y$ ).Di mana laju penyerangan ( $\alpha$ ) dikalikan dengan bilangan $\mathrm{y}$ dan bilangan $\mathrm{x}$. Bilangan predator dan prey turun ketika pertemuan predator dan prey lebih sering, tetapi laju aktual dari konsumsi akan tergantung pada laju penyerangan $(\alpha)$. Persamaan populasi prey menjadi:

$$
\frac{d x}{d t}=\operatorname{rx}\left(1-\frac{x}{K}\right)-\alpha x y
$$

Adapun analisis numerik model predator prey adalah :

1. Titik ekuilibrium model (2.15) adalah $\mathrm{E}_{0}=$ $(0,0), \quad E_{1}=(\mathrm{K}, 0)$ dan $\mathrm{E}^{*}=\left(\mathrm{x}^{*}, \mathrm{y}^{*}\right)=$ $\left(\frac{c}{\beta}, \frac{r(K \beta-c)}{\alpha \beta K}\right)$. Agar mendapatkan sebuah 
titik ekuilibrium yang positif diasumsikan bahwa $K \beta-c>0$. Matriks Jacobian dari model (2.15) yaitu

$$
J=\left(\begin{array}{cc}
r-\frac{2 r x}{K}-\alpha y & -\alpha x \\
\beta y & -c+\beta x
\end{array}\right)
$$

2. Matriks Jacobian pada titik ekuilibrium $E^{*}$ adalah

$$
J=\left(\begin{array}{cc}
\frac{-r c}{\beta K} & \frac{-\alpha c}{\beta} \\
\frac{r \beta K-r c}{\alpha K} & 0
\end{array}\right)
$$

3. Persamaan karakteristik dari Matriks Jacobian di atas adalah

$$
f(\lambda)=\lambda^{2}+\frac{r c}{\beta K} \lambda+\frac{c}{\beta K}(r \beta K-r c)
$$

4. Misalkan $P=\frac{r c}{\beta K}$ dan $Q=\frac{c}{\beta K}(r \beta K-r c)$ maka nilai eigen dari matrik Jacobian di atas adalah

$$
\lambda_{1,2}=\frac{-P \pm \sqrt{P^{2}-4 Q}}{2}
$$

Karena $\mathrm{P}$ dan $\mathrm{Q}$ adalah bilangan positif, maka nilai eigen dari $\mathrm{P}$ dan $\mathrm{Q}$ memiliki bagian yang riil negatif. Hal ini berarti bahwa titik ekuilibrium $\mathrm{E}^{*}$ adalah asimtot lokal stabil. Karena $K \beta-c>0$ maka titik ekuilibrium $E^{*}$ juga asimtot global stabil.

\section{Model Populasi Predator Prey dengan Perlambatan}

Waktu perlambatan (perlambatan) sangat penting untuk diperhitungkan di dunia permodelan karena keputusan seringkali dibuat berdasarkan pada keterangan realita. Merupakan hal yang penting untuk mempertimbangkan model populasi dimana laju pertumbuhan populasi tidak hanya tergantung pada ukuran populasi pada satu waktu tertentu tetapi juga tergantung pada ukuran populasi pada $(t-\tau)$, dimana $\tau$ adalah waktu perlambatan.

Berikut adalah model populasi predatorprey dengan perlambatan yang diperkenalkan olah May pada tahun 1974:

$\frac{d x(t)}{d t}=r x(t)\left(1-\frac{x(t-\tau)}{K}\right)-\alpha x(t) y(t)$

$\frac{d y(t)}{d t}=-c y(t)+\beta x(t) y(t)$

dimana $r, K, \tau, \alpha, c$ dan $\beta$ adalah konstanta positif. Parameter model (2.16) yaitu :

$\mathrm{K}$ = daya kapasitas

$\mathrm{r} \quad=$ laju pertumbuhan intrinsik prey

c = laju kematian jika predator tanpa prey $\alpha \quad=$ laju perpindahan dari prey ke predator

$\beta$ = laju perpindahan dari predator ke prey

$\tau=$ waktu perlambatan

Untuk menganalisis kestabilan titik ekuilibrium dari model dengan perlambatan, harus mengelinierisasi model di sekitar titik ekuilibrium, kemudian memeriksa nilai eigen pada persamaan karakteristik. Titik ekuilibrium asimtot stabil jika dan hanya jika akar-akar dari persamaan karakteristik mempunyai bagian real negatif . Langkah selanjutnya dalam menganalisis titik ekuilibrium dari model predator-prey dengan perlambatan dibutuhkan teorema berikut:

\section{Teorema 3}

Misalkan $K \beta-c>0$ dan $\tau_{k}^{ \pm}$didefinisikan pada persamaan (2.16) berbentuk :

$\tau_{k}^{+}=\frac{\pi / 2}{\omega_{+}}+\frac{2 k \pi}{\omega_{+}} \cdot$ dan $\tau_{k}^{-}=\frac{3 \pi / 2}{\omega_{-}}+\frac{2 k \pi}{\omega_{-}}$,

maka terdapat sebuah bilangan positif $m$ sedemikian hingga $m$ merubah dari stabil ke tidak stabil dan ke stabil. Dengan kata lain, ketika $\tau \in\left[0, \tau_{0}^{+}\right) \cup\left(\tau_{0}^{-}, \tau_{1}^{+}\right) \cup \ldots \cup\left(\tau_{m-1}^{-}, \tau_{m}^{+}\right), \quad$ titik ekuilibrium $E^{*}$ pada model (3.2) stabil, dan ketika $\tau \in\left[\tau_{0}^{+}, \tau_{0}^{-}\right) \cup\left(\tau_{1}^{+}, \tau_{1}^{-}\right) \cup \ldots \cup\left(\tau_{m-1}^{+}, \tau_{m-1}^{-}\right)$, titik ekuilibrium $E^{*}$ tidak stabil. Oleh karena itu ada bifurkasi untuk $\tau=\tau_{k}^{ \pm}, \mathrm{k}=0,1,2, \ldots$

\section{Bukti}

Diketahui bahwa titik ekuilibrium $E^{*}$ stabil untuk $\tau=0$. Maka untuk membuktikan teorema 3 hanya dibutuhkan kondisi secara transversal.

$\left.\frac{d(\operatorname{Re} \lambda)}{d \tau}\right|_{\tau=\tau_{k}^{+}}>0 \quad$ dan $\left.\quad \frac{d(\operatorname{Re} \lambda)}{d \tau}\right|_{\tau=\tau_{k}^{-}}<0$.

Persamaan $\lambda^{2}+\lambda P e^{-\lambda \tau}+Q=0$ dideferensialkan menjadi

$$
\begin{aligned}
& 2 \lambda \frac{d \lambda}{d \tau}+P e^{-\lambda \tau} \frac{d \lambda}{d \tau} \\
& +\lambda P e^{-\lambda \tau}\left(-\tau \frac{d \lambda}{d \tau}-\lambda\right)=0, \\
& \left(2 \lambda+(1-\lambda \tau) P e^{-\lambda \tau}\right) \frac{d \lambda}{d \tau}=\lambda^{2} P e^{-\lambda \tau} .
\end{aligned}
$$

Agar lebih mudah dipahami, maka $\left(\frac{d \lambda}{d \tau}\right)$ diubah menjadi $\left(\frac{d \lambda}{d \tau}\right)^{-1}$. Maka didapatkan :

$$
\begin{aligned}
\left(\frac{d \lambda}{d \tau}\right)^{-1} & =\frac{2 \lambda e^{\lambda \tau}+P(1-\lambda \tau)}{\lambda^{2} P} \\
& =\frac{2 \lambda e^{\lambda \tau}+P}{\lambda^{2} P}-\frac{\tau}{\lambda}
\end{aligned}
$$


dari persamaan karakteristik $\lambda^{2}+\lambda P e^{-\lambda \tau}+Q=0$ diketahui bahwa

$$
e^{\lambda \tau}=\frac{-\lambda P}{\lambda^{2}+Q} e^{\lambda \tau}=
$$

Maka didapatkan

$$
\left(\frac{d \lambda}{d \tau}\right)^{-1}=\frac{-\lambda^{2}+Q}{\lambda^{2}\left(\lambda^{2}+Q\right)}-\frac{\tau}{\lambda}
$$

Oleh karena itu

$$
\begin{aligned}
\operatorname{sign}\left(\frac{d(\operatorname{Re} \lambda)}{d \tau}\right)_{\lambda=i \omega} & =\operatorname{sign}\left(\operatorname{Re}\left(\frac{d \lambda}{d \tau}\right)^{-1}\right)_{\lambda=i \omega} \\
= & \operatorname{sign}\left(\operatorname{Re}\left[\frac{-1}{\lambda^{2}+Q}\right]_{\lambda=i \omega}\right. \\
& \left.+\operatorname{Re}\left[\frac{Q}{\lambda^{4}+\lambda^{2} Q}\right]_{\lambda=i \omega}\right) \\
= & \operatorname{sign}\left(\frac{-1}{-\omega^{2}+Q}+\frac{Q}{\omega^{4}-\omega^{2} Q}\right) \\
= & \operatorname{sign}\left(\frac{\omega^{4}-Q^{2}}{\omega^{2}\left(\omega^{2}-Q\right)^{2}}\right) \\
= & \operatorname{sign}\left(\omega^{4}-Q^{2}\right)
\end{aligned}
$$

Karena $\omega^{4}-Q^{2}=2 \omega^{4}-\left(P^{2}+2 Q\right) \omega^{2}$

Maka didapatkan

$$
\begin{aligned}
\operatorname{sign}\left(\frac{d(\operatorname{Re} \lambda)}{d \tau}\right)_{\lambda=i \omega} & =\operatorname{sign}\left(2 \omega^{4}-\left(P^{2}+2 Q\right) \omega^{2}\right) \\
& =\operatorname{sign}\left(2 \omega^{2}-\left(P^{2}+2 Q\right)\right)
\end{aligned}
$$

Jadi dapat dibuktikan bahwa kondisi transversal telah terpenuhi. (Syamsuddin, 2006:4.10)

\section{PEMBAHASAN}

\subsection{Analisis Pembentukan Model Predator Prey dengan Perlambatan}

Berikut adalah model populasi predatorprey dengan perlambatan yang diperkenalkan olah May pada tahun 1974:

$\frac{d x(t)}{d t}=r x(t)\left(1-\frac{x(t-\tau)}{K}\right)-\alpha x(t) y(t)$

$\frac{d y(t)}{d t}=-c y(t)+\beta x(t) y(t)$

dimana $r, K, \tau, \alpha, c$ dan $\beta$ adalah konstanta positif. Parameter model (3.1) yaitu :

$\mathrm{K}$ = daya kapasitas

$\mathrm{r} \quad$ = laju pertumbuhan intrinsik prey

$\mathrm{c} \quad=$ laju kematian jika predator tanpa prey

$\alpha \quad=$ laju perpindahan dari prey ke predator

$\beta \quad$ = laju perpindahan dari predator ke prey

$\tau \quad=$ waktu perlambatan

Dimulai dengan menganalisis pembentukan model predator. Pertama, dengan memperhatikan apa yang terjadi pada populasi predator ketika tidak adanya prey, tanpa sumber makanan, bilangannya diharapkan berkurang secara eksponensial, dideskripikan oleh persamaan di bawah ini :

$$
\frac{d y}{d t}=-c y
$$

Persamaan ini menggunakan hasil kali dari bilangan predator (y) dan kelajuan kematian predator (c). Tanda negatif pada bagian kanan persamaan untuk mendeskripsikan penurunan kelajuan dari populasi predator terhadap pengaruh waktu. Dengan adanya prey (sebagai konsumsi predator) pengurangan ini dilawan oleh laju kelahiran predator, yang ditentukan oleh laju konsumsi $(\beta x y)$. Dimana laju penyerangan $(\beta)$ dikalikan dengan bilangan $y$ dan bilangan $\mathrm{x}$. Bilangan predator dan prey naik ketika pertemuan predator dan prey lebih sering, tetapi laju aktual dari konsumsi akan tergantung pada laju penyerangan ( $\beta$ ). Persamaan populasi predator menjadi

$$
\frac{d y}{d t}=-c y+\beta x y
$$

Perkalian $\beta \mathrm{y}$ adalah tanggapan predator secara numerik atau peningkatan perkapita dari fungsi prey yang melimpah. Dan untuk perkalian $\beta$ xy menunjukkan bahwa kenaikan populasi predator sebanding dengan perkalian dan prey yang melimpah.

Selanjutnya dianalisis populasi prey. Diharapkan tanpa serangan predator, bilangan prey akan naik secara eksponensial. Persamaan di bawah ini mendeskripsikan laju kenaikan populasi prey dengan pengaruh waktu, dimana $r$ adalah laju pertumbuhan intrinsik prey dan $\mathrm{x}$ adalah jumlah dari populasi prey.

$$
\frac{d x}{d t}=r x
$$

Di hadapan predator, bagaimanapun juga populasi prey mencegah agar tidak terjadi peningkatan eksponensial secara terus-menerus. Karena model predator-prey memiliki waktu yang kontinu dan mengisyaratkan tentang model pertumbuhan populasi maka termasuk dalam model logistik. Jadi persamaan di atas menjadi:

$$
\frac{d x}{d t}=r x\left(1-\frac{x}{K}\right)
$$

Dengan adanya predator, kenaikan ini dilawan oleh laju kematian prey karena adanya penyerangan dari predator, yang ditentukan oleh laju konsumsi ( $\alpha x y$ ). Dimana laju penyerangan ( $\alpha$ ) dikalikan dengan bilangan y dan bilangan $\mathrm{x}$. Bilangan predator dan prey turun ketika pertemuan predator dan prey lebih sering, tetapi laju aktual dari konsumsi akan tergantung pada 
laju penyerangan $(\alpha)$. Persamaan populasi prey menjadi:

$$
\frac{d x}{d t}=r x\left(1-\frac{x}{K}\right)-\alpha x y
$$

Karena dalam kondisi tertentu pada populasi prey tedapat keterlambatan (waktu $\tau$ ) pada laju kelahiran maka persamaan populasi menjadi :

$$
\frac{d x}{d t}=r x\left(1-\frac{(x-\tau)}{K}\right)-\alpha x y
$$

Jadi sistem persamaan diferensial model predator prey dengan perlambatan adalah :

$$
\begin{aligned}
& \frac{d x(t)}{d t}=r x(t)\left(1-\frac{x(t-\tau)}{K}\right)-\alpha x(t) y(t) \\
& \frac{d y(t)}{d t}=-c y(t)+\beta x(t) y(t)
\end{aligned}
$$

\subsection{Analisis Model Predator Prey dengan Perlambatan}

Berikut ini adalah pembahasan tentang analisis model predator-prey dengan mempertimbangkan waktu perlambatan, May (1974) telah menunjukkan model sistem persamaan diferensial di bawah ini :

$$
\begin{aligned}
& \frac{d x(t)}{d t}=r x(t)\left(1-\frac{x(t-\tau)}{K}\right)-\alpha x(t) y(t) \\
& \frac{d y(t)}{d t}=-c y(t)+\beta x(t) y(t)
\end{aligned}
$$

Dimana $r, K, \tau, \alpha, c$ dan $\beta$ adalah konstanta positif. Model (3.2) memuat sebuah single diskrit perlambatan.

Jika masa perlambatan dari prey adalah $\tau$, maka fungsi laju pertumbuhan perkapita akan membawa sebuah waktu perlambatan $\tau$. Di dalam tulisan ini akan dianalisis pengaruh waktu perlambatan terhadap kestabilan titik ekuilibrium dari sistem.

Titik equilibrium model (3.2) ada 2 yaitu :

1. Titik $(0,0)$

2. Titik kedua yang memenuhi $\frac{d y}{d t}=0$ dan $\frac{d x}{d t}=0$ yaitu :

$$
\begin{aligned}
\frac{d y}{d t} & =0 \\
-c y+\beta x y & =0 \\
x & =\frac{c y}{\beta y} \\
x & =\frac{c}{\beta}
\end{aligned}
$$

dan

$$
\begin{aligned}
\frac{d x}{d t} & =0 \\
r x-r x^{2}-\alpha x y & =0 \\
y & =\frac{r x^{2}-r x}{\alpha x} \\
y & =\frac{r x-r}{\alpha} \\
y & =\frac{\frac{r c}{\beta K}-r}{\alpha} \\
y & =\frac{r(K \beta-c)}{\alpha \beta K}
\end{aligned}
$$

Jadi titik ekuilibrium yang kedua yaitu

$$
\left(\frac{c}{\beta}, \frac{r(K \beta-c)}{\alpha \beta K}\right) .
$$

Dalam tulisan ini akan difokuskan pada analisis kestabilan dari titik equilibrium $E^{*}$, karena titik equilibrium tersebut berada di kuadran positif dan asimtot stabil ketika tidak ada waktu perlambatan. Untuk memahami kestabilan lokal dari titik equilibrium $\mathrm{E}^{*}$ pada model (3.2), akan dianalisis model sistem persamaaan diferensial nonlinear setelah model tersebut dilinearisasi. Misalkan $u(t)=x(t)-x^{*}$ dan $v(t)=y(t)-y^{*}$. Maka setelah disubtitusi ke dalam model (3.2) didapatkan :

$$
\begin{aligned}
\dot{u}(t)= & r\left(u(t)+x^{*}\right)\left(1-\frac{u(t-\tau)+x^{*}}{K}\right) \\
& -\alpha\left(u(t)+x^{*}\right)\left(v(t)+y^{*}\right) \\
\dot{v}(t)= & -c\left(v(t)+y^{*}\right)+\beta\left(u(t)+x^{*}\right)\left(v(t)+y^{*}\right)
\end{aligned}
$$

atau

$$
\begin{aligned}
\dot{u}(t)= & r u(t)+r x^{*}-\frac{r}{K} u(t) u(t-\tau) \\
& -\frac{r}{K} x^{*} u(t-\tau)-\frac{r}{K} x^{*} u(t)-\frac{r}{K}\left(x^{*}\right)^{2} \\
& -\alpha u(t) v(t)-\alpha x^{*} v(t)-\alpha y^{*} u(t)-\alpha x^{*} y^{*} \\
\dot{v}(t)= & -c v(t)-c y^{*}+\beta u(t) v(t)+\beta y^{*} u(t) \\
& +\beta x^{*} v(t)+\beta x^{*} y^{*}
\end{aligned}
$$

Setelah menyederhanakan dan mengabaikan hubungan hasil kali, didapat sebuah model linear:

$$
\begin{aligned}
& \dot{u}(t)=-\frac{r}{K} x^{*} u(t-\tau)-\alpha x^{*} v(t) \\
& \dot{v}(t)=\beta y^{*} u(t) .
\end{aligned}
$$

Menganalisis kestabilan lokal dari titik ekulibrium titik $E^{*}$ pada model (3.2) ekuivalen dengan menganalisis kestabilan dari titik ekulibrium nol pada model linear. Dari model yang telah dilinearisasi didapatkan matrik Jacobian sebagai berikut : 


$$
J=\left(\begin{array}{ll}
\frac{\partial f_{1}}{\partial u} & \frac{\partial f_{1}}{\partial v} \\
\frac{\partial f_{2}}{\partial u} & \frac{\partial f_{2}}{\partial v}
\end{array}\right)
$$

Misalkan $f_{1}=\dot{u}(t)$ dan $f_{1}=\dot{v}(t)$ maka didapatkan matriks Jacobian sebagai berikut:

$$
J=\left(\begin{array}{cc}
-\frac{r}{K} x^{*} e^{-\lambda \tau} & -\alpha x^{*} \\
\beta y^{*} & 0
\end{array}\right)
$$

Polinom karakteristik dari $J$ adalah :

$$
\begin{aligned}
\operatorname{det}(\lambda I-J) & =\operatorname{det}\left(\left(\begin{array}{ll}
\lambda & 0 \\
0 & \lambda
\end{array}\right)-\left(\begin{array}{cc}
-\frac{r}{K} x^{*} e^{-\lambda \tau} & -\alpha x^{*} \\
\beta y^{*} & 0
\end{array}\right)\right) \\
& =\operatorname{det}\left(\begin{array}{cc}
\lambda+\frac{r}{K} x^{*} e^{-\lambda \tau} & \alpha x^{*} \\
-\beta y^{*} & \lambda
\end{array}\right) \\
& =\lambda^{2}+\lambda \frac{r}{K} x^{*} e^{-\lambda \tau}+\alpha \beta x^{*} y^{*}
\end{aligned}
$$

Jadi persamaan karakteristik dari $J$ adalah sebagai berikut :

$$
\lambda^{2}+\lambda P e^{-\lambda \tau}+Q=0
$$

dimana

$$
\begin{aligned}
& P=\frac{r}{K} x^{*} \text { dan } \\
& Q=\alpha \beta x^{*} y^{*} .
\end{aligned}
$$

Untuk $\tau=0$ persamaan karakteristik menjadi :

$$
\lambda^{2}+\lambda P+Q=0
$$

yang memiliki akar-akar

$$
\lambda_{1,2}=\frac{-P \pm \sqrt{P^{2}-4 Q}}{2} .
$$

Karena P dan Q keduanya adalah bilangan positif, nilai eigen dari persamaan karakteristik (3.4) memiliki bagian riil negatif.

Sedangkan untuk $\tau \neq 0$, jika $\lambda=i \omega, \omega>0$, adalah sebuah akar dari persamaan karakteristik (3.4) maka didapatkan :

$-\omega^{2}+i P \omega e^{-i \omega \tau}+Q=0$,

$-\omega^{2}+i P \omega \cos (\omega \tau)+P \omega \sin (\omega \tau)+Q=0$.

Dengan memisahkan bagian riil dan imajinernya, didapatkan :

$-\omega^{2}+P \omega \sin (\omega \tau)+Q=0$,

$P \omega \cos (\omega \tau)=0$.

Kedua persamaan diatas dikuadratkan menjadi:

$P^{2} \omega^{2} \sin ^{2}(\omega \tau)=\omega^{4}-2 Q \omega^{2}+Q^{2}$

$P^{2} \omega^{2} \cos ^{2}(\omega \tau)=0$.

Kedua persamaan diatas dijumlahkan, menjadi: $P^{2} \omega^{2} \sin ^{2}(\omega \tau)+P^{2} \omega^{2} \cos ^{2}(\omega \tau)=\omega^{4}-2 Q \omega^{2}+Q^{2}$

$$
P^{2} \omega^{2}=\omega^{4}-2 Q \omega^{2}+Q^{2}
$$

Kemudian dikelompokkan didapatkan polinomial pangkat empat:
$\omega^{4}-\left(P^{2}+2 Q\right) \omega^{2}+Q^{2}=0$,

Akar-akar dari persamaan diatas yaitu:

$$
\omega_{ \pm}^{2}=\frac{1}{2}\left\{\left(P^{2}+2 Q\right) \pm \sqrt{\left(P^{2}+2 Q\right)^{2}-4 Q^{2}}\right\} \text {, }
$$

atau

$$
\omega_{ \pm}^{2}=\frac{1}{2}\left\{\left(P^{2}+2 Q\right) \pm \sqrt{P^{4}+4 P^{2} Q}\right\} .
$$

Dari persamaan (3.7) dapat diketahui bahwa ada solusi positif pada $\omega_{+}^{2}$. Selanjutnya dapat ditemukan nilai $\tau_{k}^{ \pm}$dari subtitusi $\omega_{ \pm}^{2}$ ke dalam persamaan (3.6) dan penyelesaian untuk $\tau$, yaitu:

$$
\begin{aligned}
\cos \omega \tau & =0 \\
\omega \tau & =\cos ^{-1} 0 \\
\omega \tau^{+} & =90+2 k \pi \\
\omega \tau^{-} & =270+2 k \pi
\end{aligned}
$$

Didapatkan

$$
\begin{aligned}
& \tau_{k}^{+}=\frac{\pi / 2}{\omega_{+}}+\frac{2 k \pi}{\omega_{+}}, \\
& \tau_{k}^{-}=\frac{3 \pi / 2}{\omega_{-}}+\frac{2 k \pi}{\omega_{-}}, \quad \mathrm{k}=0,1,2, \ldots
\end{aligned}
$$

Sebagai contoh model (3.2) dimasukkan parameter $\mathrm{r}=1, \mathrm{~K}=200, \alpha=0.15, \mathrm{c}=1$ dan $\beta$ $=0.1$. Maka didapatkan beberapa grafik sebagai berikut:

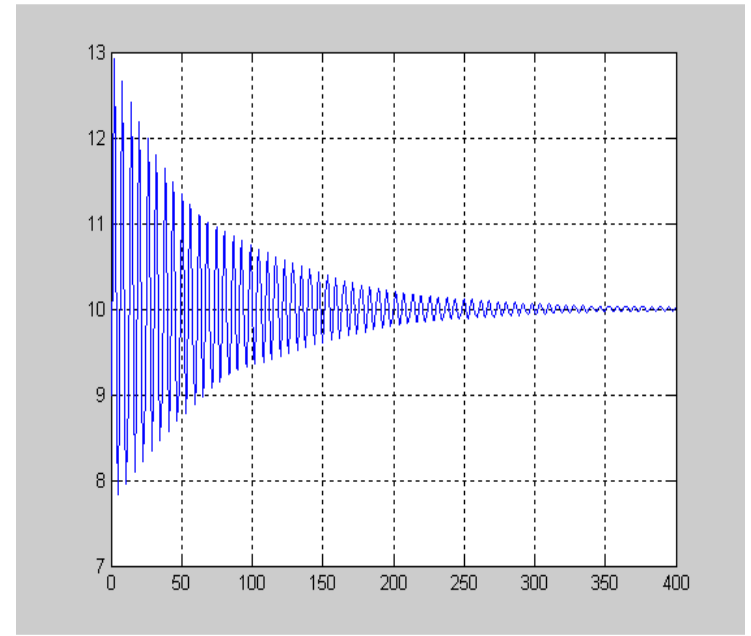

Gambar 3.1 Grafik Persamaan Diferensial Dari Prey $(\mathrm{x}(\mathrm{t}))$ dengan $\mathrm{x}(0)=9$ dan $\tau=0.5$ 


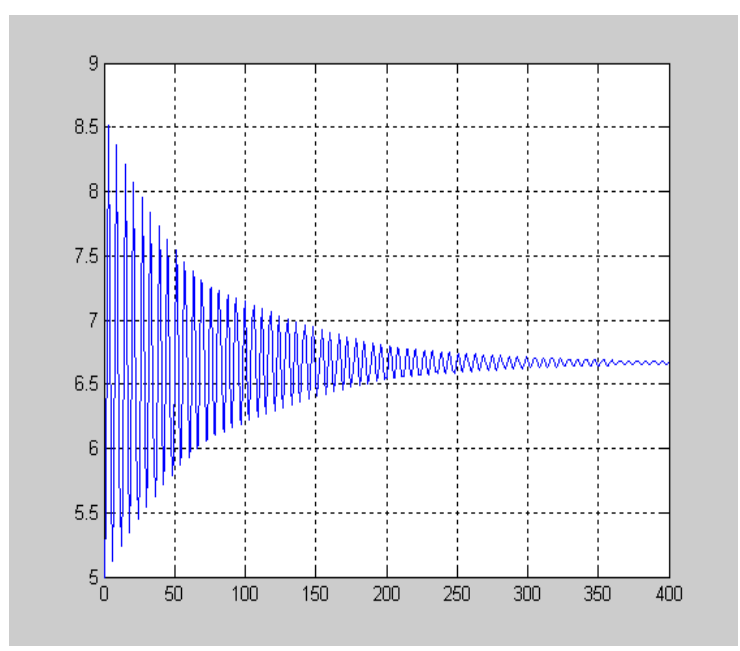

Gambar 3.2 Grafik Persamaan Diferensial dari Predator $(\mathrm{y}(\mathrm{t}))$ dengan $\mathrm{y}(0)=9$ dan $\tau=0.5$

Dan berikut ini adalah jumlah populasi predator dan dan prey pada saat nilai perlambatan $\tau=0.5$ :

\begin{tabular}{ccc}
\hline Hari ke & Prey $(\mathbf{x}(\mathbf{t}))$ & Predator $(\mathbf{y}(\mathbf{t}))$ \\
\hline 1 & 9,00000 & 5,00000 \\
2 & 11,16000 & 5,58000 \\
3 & 12,91882 & 7,20870 \\
$\cdot$ & $\cdot$ & $\cdot$ \\
$\cdot$ & $\cdot$ & $\cdot$ \\
$\cdot$ & $\cdot$ & $\cdot$ \\
400 & 9,99372 & 6,65449 \\
\hline
\end{tabular}

Dari grafik (3.1) dan (3.2) di atas dapat diamati bahwa dengan nilai perlambatan $\tau=0.5$ titik ekuilibrium $(10 ; 6.33)$ sistem persamaan diferensial model predator-prey stabil.

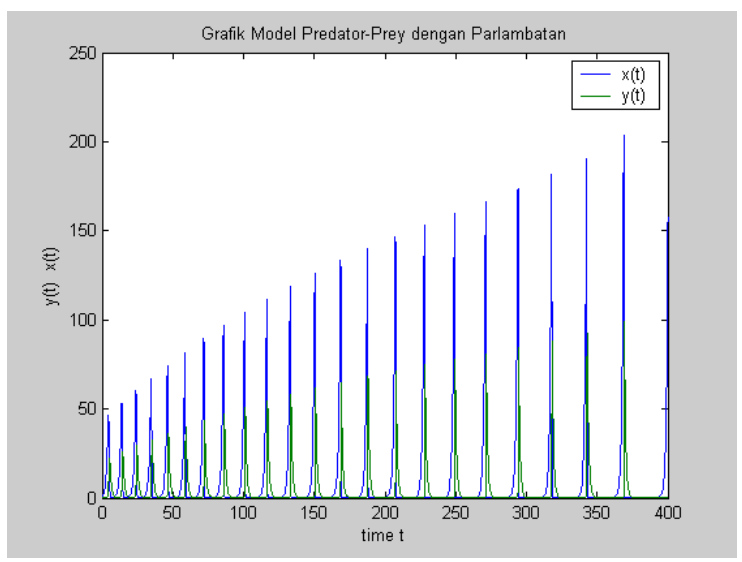

Gambar 3.3 Grafik Jumlah Populasi Predator dan Prey dengan $\tau=2.7$

Dari grafik (3.3) dapat diamati bahwa dengan nilai perlambatan $\tau=2.7$ titik ekuilibrium $(10 ; 6.33)$ sistem persamaan diferensial model predator-prey tidak stabil.
Dari persamaan (3.9) yang telah diubah ke dalam bentuk radian didapatkan nilai-nilai perlambatan sebagai berikut :

$$
\begin{array}{ll}
\tau_{0}^{+}=1.57080 & \tau_{0}^{-}=5.23599 \\
\tau_{1}^{+}=7.85398 & \tau_{1}^{-}=12.21730 \\
\tau_{2}^{+}=14.13717 & \tau_{2}^{-}=19.19862 \\
\tau_{3}^{+}=20.42035 & \tau_{3}^{-}=26.17994 \\
\tau_{4}^{+}=26.70354 & \tau_{4}^{-}=33.16126 \\
\tau_{5}^{+}=32.98672 & \tau_{5}^{-}=40.14257
\end{array}
$$

Berdasarkan teorema 3 dengan nilai perlambatan $\tau \in(0,1.57080) \cup(5.23599,7.85398) \cup$

$(12.21730,1413717) \cup(19.19862,20.42035) \cup$ $(26.17994,26.70354) \cup(33.16126,32.98672)$

titik ekuilibrium $(10 ; 6.33)$ pada sistem persamaan diferensial model predator-prey stabil. Sedangkan dengan nilai perlambatan $\tau \in(1.57080,5.23599) \cup(7.85398,12.21730) \cup$

$(14.13717,19.19882) \cup(20.42035 \cup 26.17994) \cup$ $(26.70354,3316126) \cup(32.98672,40.14257)$

titik ekuilibrium $(10 ; 6.33)$ pada sistem persamaan diferensial model predator-prey tidak stabil.

Untuk mengetahui pengaruh waktu perlambatan terhadap titik ekuilibrium sistem, dapat diamati dengan membandingkan grafik antara model dengan waktu perlambatan dan model tanpa waktu perlambatan.

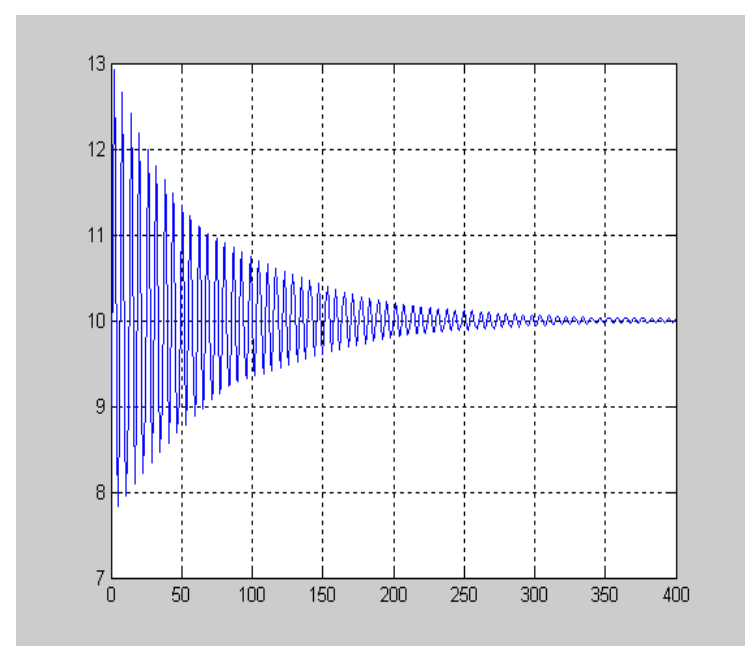

Gambar 3.4 Grafik Persamaan Diferensial dari Prey $(\mathrm{x}(\mathrm{t}))$ Tanpa Waktu Perlambatan 


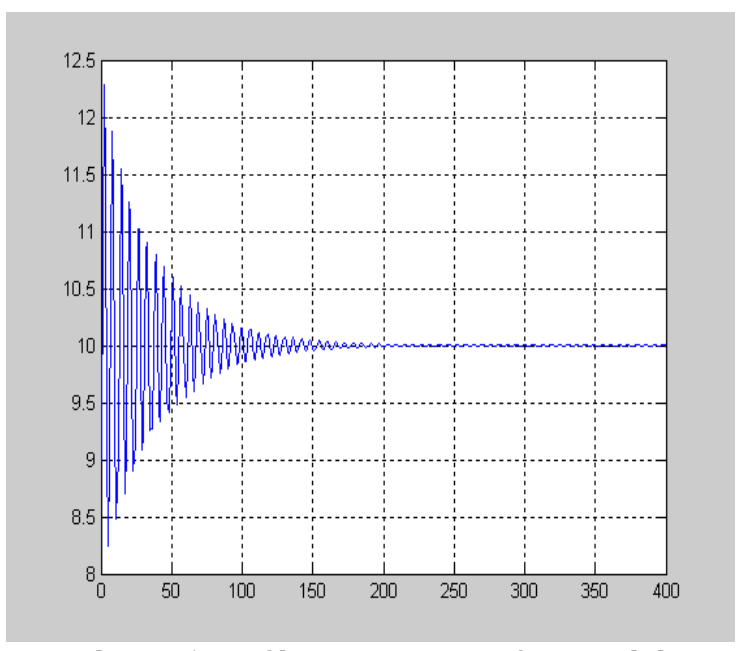

Gambar 3.5 Grafik Persamaan Diferensial dari Prey $(\mathrm{x}(\mathrm{t}))$ dengan Waktu Perlambatan $\tau=0.5$

Adapun nilai numerik solusi persamaan diferensial dengan waktu perlambatan dan tanpa waktu perlambatan, sebagai berikut :

\begin{tabular}{ccc}
\hline Hari ke & $\begin{array}{c}\text { Dengan Waktu } \\
\text { Perlambatan }\end{array}$ & $\begin{array}{c}\text { Tanpa Waktu } \\
\text { Perlambatan }\end{array}$ \\
\hline 1 & 9,00000 & 9,00 \\
2 & 11,16000 & 10,85 \\
3 & 12,91882 & 12,28 \\
$\cdot$ & $\cdot$ & $\cdot$ \\
$\cdot$ & $\cdot$ & $\cdot$ \\
$\cdot$ & $\cdot$ & $\cdot$ \\
280 & 10,04294 & 10,00 \\
\hline
\end{tabular}

Dari nilai numerik pada tabel di atas dapat diamati bahwa titik ekuilibrium $(10 ; 6.33)$ pada sistem persamaan diferensial model predatorprey tanpa waktu perlambatan stabil, terjadi pada hari ke-235. Sedangkan titik ekuilibrium $(10 ; 6.33)$ sistem persamaan diferensial dengan waktu perlambatan stabil, terjadi pada hari ke251, lebih lambat jika dibandingkan dengan kestabilan titik ekuilibrium sistem persamaan diferensial tanpa waktu perlambatan.

\section{PENUTUP}

Berdasarkan hasil penelitian dapat ditarik kesimpulan tentang analisis pembentukan model matematika, yaitu :

1. Analisis Pembentukan Model Predator dengan Perlambatan

a. Terjadi penurunan jumlah populasi predator karena tidak ada prey sebagai sumber makanan. Oleh karena itu persamaannya bertanda negatif.

b. Terjadi kenaikan jumlah populasi predator karena adanya laju kelahiran predator yang ditentukan oleh laju konsumsi predator.
2. Analisis Pembentukan Model Prey

a. Terjadi kenaikan jumlah populasi prey karena tidak adanya predator sebagai pemangsa. Oleh karena itu persamaannya bertanda positif.

b. Model prey termasuk dalam model logistik.

c. Terjadi penurunan jumlah populasi prey karena adanya laju kematian prey dengan adanya penyerangan dari predator.

Selanjutnya untuk mengetahui pengaruh waktu perlambatan terhadap kestabilan titik ekuilibrium pada sistem persamaan diferensial model predator-prey yaitu dengan menganalisis titik ekuilibrium $\left(\frac{c}{\beta}, \frac{r(K \beta-c)}{\alpha \beta K}\right)$. Karena titik equilibrium tersebut berada di kuadran positif dan asimtot stabil ketika tidak ada waktu perlambatan. Dari hasil analisis pada pembahasan didapatkan nilai perlambatan $\tau \in(0,1.57080) \cup(5.23599,7.85398) \cup$

$(12.21730,1413717) \cup(19.19862,20.42035) \cup$

$(26.17994,26.70354) \cup(33.16126,32.98672)$

titik ekuilibrium $(10 ; 6.33)$ pada sistem persamaan diferensial model predator-prey stabil. Sedangkan dengan nilai perlambatan $\tau \in(1.57080,5.23599) \cup(7.85398,12.21730) \cup$

$(14.13717,19.19882) \cup(20.42035 \cup 26.17994) \cup$ $(26.70354,3316126) \cup(32.98672,40.14257)$

titik ekuilibrium $(10 ; 6.33)$ pada sistem persamaan diferensial model predator-prey tidak stabil.

\section{DAFTAR PUSTAKA}

[1] Abdurrahman, bin Muhammad. 2008. Tafsir Al-Usyr Al-Akhir, http://www.tafseer.info. Diakses tanggal 7 Juli 2009

[2] Al Katsir, Abul Fida'. 1993. Tafsir Ibnu Katsir. Beirut : Darul Fikri.

[3] Al Mahalli. Jalaluddin. 1990. Tafsir Jalalain. Toha Putra : Semarang.

[4] Al Maraghi, Musthofa Ahmad. 1971. Tafsir Al Maraghi. Beirut : Darul Fikri

[5] Anonim. 2009. Proses Pemodelan Matematika,http://www.sipoel.unimed.in/ file.php/44/COURSE/BAB_II/BAB_2.doc. Diakses tanggal 19 Mei 2008.

[6] Ayres, Frank. 1992. Persamaan Diferensial dalam Satuan SI Metric. Jakarta : Erlangga

[7] Baiduri. 2002. Persamaan Diferensial dan Matematika Model. Malang: UMM Press. 
[8] Beals. 1999. Predator Prey Dynamics: Lotka Voltera, http://www.google.com/htm. Diakses tanggal 7 Juli 2009

[9] Baiduri. 2002. Persamaan Diferensial dan Matematika Model. Malang: UMM Press

[10] Finizio dan Ladas. 1998. Penerapan Diferensial Biasa dengan Penerapan Modern, Edisi Kedua. Terjemahan Widiarti Santoso. Jakarta : Erlangga.

[11] Kasanah, Srinur. 2007. Analisis Model Matematika pada Interaksi Leukimia Mielogenous Kronik (CML) dengan Sel T. Skripsi tidak dipublikasikan. Malang: UIN Malang.

[12] Murray, JD. 2002. Mathematical Biology I. An Introduction Third Edition. New York: Springer
[13] Neuhauser, Claudia. 2004. Calculus for Biology and Medicine. New Jersey: Pearson Education

[14] Reece, Campbell. 2004. Biologi. Jakarta: Erlangga.

[15] Shihab, M. Quraish. 2002. Tafsir Al-Misbah. Jakarta: Lentera Hati.

[16] Sirin, Khaeron. 2008. Membangun Fiqh Bumi, http://www.ptiq.ac.id/index.php? option $=$ com_content\&task=view\&id=38\&Item id=34. Diakses tanggal 14 Juli 2009.

[17] Toaha, Syamsuddin. 2006. Stability Analysis of Sum Population Model with Time Delay and Harvesting. Makasar. Department of Mathematics Hasanuddin University

[18] Yahya, Harun. 2009. Menyingkap Rahasia Alam Semesta, http://www.harunyahya.com /indo/buku/menyingkap010.htm. Diakses tanggal 7 Juli 2009. 